\title{
Improved Protocol Toward 1,3,4-Oxadiazole-2(3H)-thiones and Scale-up Synthesis in the Presence of SDS as a Micelle Promoted Catalyst
}

\author{
Ayhan Yldirım* \\ Uludă̆ University, Department of Chemistry, 16059 Bursa, Turkey \\ * Corresponding author: E-mail: yildirim@uludag.edu.tr \\ Tel: +90-2242941771; fax: +90-2242941899
}

Received: 08-10-2014

\begin{abstract}
Convenient procedure for in situ cyclization of hydrazinecarbodithioate potassium salts to 1,3,4-oxadiazole-2(3H)-thiones under normal phase micellar media catalysis promoted by sodium dodecyl sulfate (SDS) as an anionic surfactant is reported. The main advantage of this procedure is to provide shorter reaction time for the completion of cyclization; scale-up synthesis is possible and the oxadiazoles were obtained in high to excellent yields (87-100\%), making the protocol an attractive alternative to the available methods.
\end{abstract}

Keywords: Hydrazides; cyclization; 1,3,4-oxadiazoles; surfactant; catalysis.

\section{Introduction}

The importance of the 1,3,4-oxadiazole ring is well established in industrial, agricultural and pharmaceutical chemistry as demonstrated by the use of its derivatives as antipyretic, analgesic, antidepressant and antimicrobial agents. As an important class of five membered heterocycles, 5-substituted-1,3,4-oxadiazole-2(3H)-thiones show a broad spectrum of biological activities. Earlier it was reported that a number of novel quinoline analogs possessing 1,3,4-oxadiazole moiety have been synthesized and screened for their potential antitumor activity. ${ }^{1}$ A series of 1,3,4-oxadiazole-2-thiones with salicylate moiety have been synthesized and evaluated for their in vitro anticancer activity. ${ }^{2}$ Jakubkiene et al. have reported that pyrimidine ring bearing 1,3,4-oxadiazole2-thiones and their 3-morpholinomethyl derivatives possess anti-inflammatory activity in vivo. ${ }^{3}$ In addition, some 1,3,4-oxadiazole-2(3H)-thiones showed in vitro antimycobacterial activity against Mycobacteriumtuberculosis $\mathrm{H}_{37} \mathrm{Rv}^{4}$ On the other hand, fatty acid based 1,3,4oxadiazoles have been synthesized with an objective to study their corrosion inhibiting properties on $\mathrm{N}-80$ steel and mild steel in $\mathrm{HCl}^{5}$

The common synthetic approaches to the 1,3,4-oxadiazole-2 $(3 H)$-thiones involve cyclization of acylhydrazi- nes in the presence of carbon disulfide in ethanolic solution of potassium hydroxide. However, this classical method of preparation generally requires a long period of time (9-36 h) ${ }^{6-11}$ Long chain aliphatic hydrazinecarbodithioate intermediates have to be heated under reflux for a long time. To the best of my knowledge, however, few studies have reported alternative synthesis methods for the preparation of 1,3,4-oxadiazole derivatives. ${ }^{12-15}$ Shahzad et al. reported an efficient solvent-free microwave assisted synthesis of 5-substituted-1,3,4-oxadiazole-2(3H)-thiones. ${ }^{12}$ They also reported that conversion of aromatic hydrazides into 1,3,4-oxadiazoles is more convenient (89-98\% yield) but in the case of aliphatic hydrazide conversion is poor and lower yield is obtained (73\%). Joshi and Karnik ${ }^{13}$ have reported microwave irradiated preparation of oxadiazoles from aromatic hydrazides. Beigi et al. reported a novel practical and efficient catalyst-free method for the synthesis of 1,3,4-oxadiazoles, which is assisted by DMF as a reaction solvent. ${ }^{14}$ But one disadvantage of this method is the use of a toxic solvent. Liu et al. developed a new strategy for solid-phase synthesis of 1,3,4oxadiazoles from resin-bound acylhydrazines, but this method also requires 8 hours for cyclization. ${ }^{15}$

Synthesizing new compounds is a common task for chemists active in preparing various drugs and special industrial chemicals. However, when large-scale synthesis 
reaction is performed, some changes in reaction kinetics may occur. In addition low reaction yields, toxicity and abundant hazardous by-products may occur.On the other hand, separation and purification steps play an important role in scale-up of any synthesis.

Therefore, after the evaluation of the disadvantages of the previously published procedures, an alternative procedure involving less toxic, readily available surfactant catalyst, taking place efficiently and quickly in a micellar media, applicable for the synthesis of long-chain aliphatic carboxylic acid hydrazide derived mono and (bis-) 1,3,4oxadiazole-2 $(3 H)$-thiones was developed. Furthermore, this strategy also provided the opportunity for clean scaleup synthesis.

\section{Results and Discussion}

Fatty acid methyl esters were prepared by sulfuric acid catalyzed esterification. For the preparation of fatty acid hydrazides 1a-i, a solution of fatty acid methyl esters in EtOH was mixed with excess of hydrazine hydrate $(100 \%)$ and the reaction mixture was refluxed for appropriate time. It was cooled and the crystalline solid separated was collected, washed and crystallized from $\mathrm{EtOH}$.

The conventional method applied for the synthesis of the previously known 1,3,4-oxadiazole-2(3H)-thiones $\mathbf{2 a - i ^ { 1 8 - 2 7 }}$ is shown in Scheme 1. The potassium hydrazinecarbodithioates required $24 \mathrm{~h}$ for complete cyclization in the absence of SDS.

The optimized SDS catalyzed reaction conditions were determined (Table 1).

Dodecanehydrazide 1c was selected as the model substrate for optimization of the micellar media reaction conditions. It was found that the SDS plays a crucial role
Table 1. Optimization of the reaction conditions for the preparation of compound 2c. ${ }^{19-21}$

\begin{tabular}{|c|c|c|c|c|}
\hline Entry & $\begin{array}{c}\text { Catalyst } \\
(10 \% \mathrm{mmol} / \mathrm{mmol})\end{array}$ & Solvent & $\begin{array}{c}\text { Time } \\
\text { (h) }\end{array}$ & $\begin{array}{l}\text { Yield } \\
(\%)\end{array}$ \\
\hline 1 & - & $\mathrm{EtOH}+\mathrm{H}_{2} \mathrm{O}$ & 2 & 53 \\
\hline 2 & SDS & $\mathrm{EtOH}+\mathrm{H}_{2} \mathrm{O}$ & 1 & 64 \\
\hline 3 & SDS & $\mathrm{EtOH}+\mathrm{H}_{2} \mathrm{O}$ & 2 & 100 \\
\hline 4 & SDS & $\mathrm{H}_{2} \mathrm{O}$ & 2 & Not isolated \\
\hline
\end{tabular}

in the success of the reaction in terms of the rate enhancement. When the reaction was carried out in the absence of SDS for $2 \mathrm{~h}$ and in the presence of SDS for $1 \mathrm{~h}$, the conversion is incomplete with starting acyl hydrazine 1c still available in the reaction medium (entries 1 and 2, Table 1). But after heating for additional $1 \mathrm{~h}$ in the presence of SDS, it is found that complete conversion could be obtained. Finally, it was found that for complete conversion in the presence of SDS the optimum reaction time is $2 \mathrm{~h}$ (entry 3, Table 1 and Scheme 2).

When water was used as a solvent in the presence of SDS under reflux conditions for $2 \mathrm{~h}$, the reaction medium was checked by TLC (Thin Layer Chromatography) and the desired cyclization product was detected but the isolation of the product $\mathbf{2} \mathbf{c}^{19,20,21}$ was very difficult due to the tedious and ineffective vacuum filtration caused by the detergent effect of SDS in water (entry 4, Table 1). One alternative solution to this problem is the extraction of the product from the aqueous medium by using a suitable organic solvent, but this is not practical for scale-up synthesis and is also not eco-friendly. Therefore, EtOH was selected as a suitable recrystallization solvent.

In some cases the yields obtained by micelle catalysis were better than those achieved by the conventional method (Table 2). Typically, surface active compounds have enough solubility in polar organic solvents<smiles>[R]C(=O)NN</smiles>

\section{1a-i}

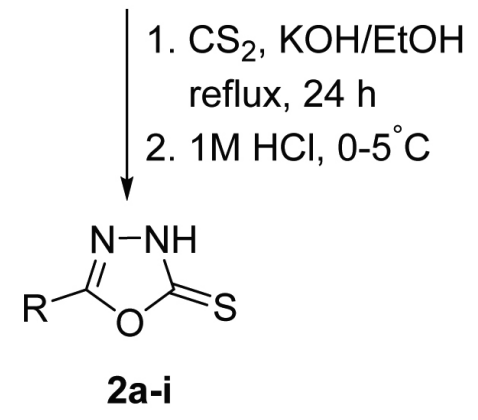

Scheme 1. Conventional synthesis of oxadiazoles. 


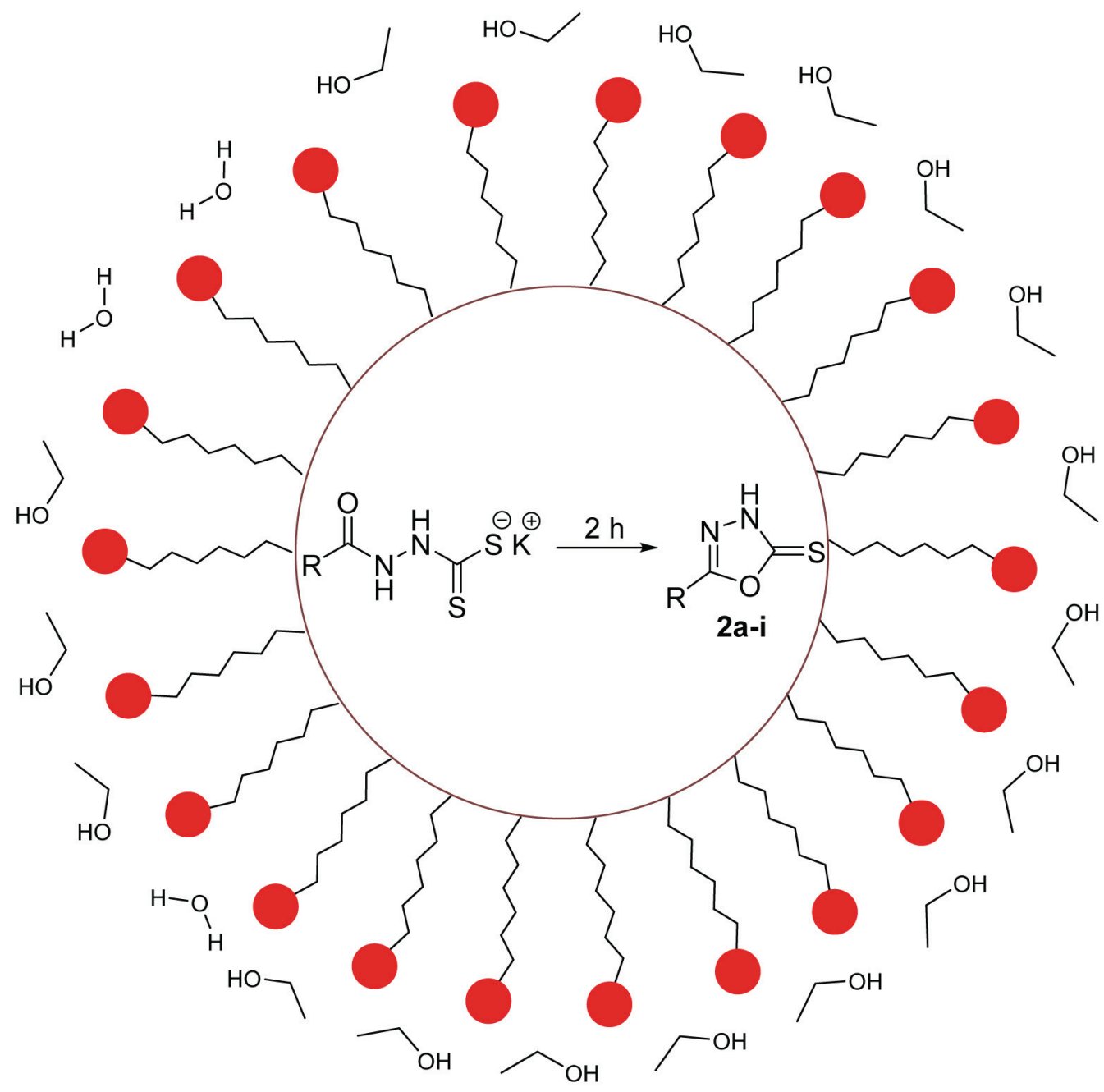

Scheme 2. Micellar media synthesis of oxadiazoles.

Table 2. Synthesis of higher 5-substituted-1,3,4-oxadiazole-2(3H)-thiones in micellar media.

\begin{tabular}{cccccc}
\hline Entry & Product & Time [h] & Yield [\%] $^{\mathbf{a}, \mathbf{b}}$ & Time [h] $^{\mathbf{c}}$ & Yield [\%] $^{\mathbf{b , c}}$ \\
\hline 1 & $\mathbf{2 a}^{20,21}$ & 24 & 91 & 2 & 92 \\
2 & $\mathbf{2 b}^{19-21}$ & 24 & 100 & 2 & 99 \\
3 & $\mathbf{2 c}^{19-21}$ & 24 & 95 & 2 & 100 \\
4 & $\mathbf{2 d}$ & 24 & 87 & 2 & 87 \\
5 & $\mathbf{2} \mathbf{e}^{19,20}$ & 24 & 82 & 2 & 100 \\
6 & $\mathbf{2 f}^{27}$ & 24 & 89 & 2 & 99 \\
7 & $\mathbf{2 g}^{27}$ & 24 & 85 & 2 & 90 \\
8 & $\mathbf{2}$ & 80 & 2 & 96 \\
9 & $\mathbf{2}$ & 24 & 84 & 2 & 99 \\
\hline
\end{tabular}

${ }^{\mathrm{a}}$ Conventional method. ${ }^{\mathrm{b}}$ Yield after crystallization. ${ }^{\mathrm{c}}$ Micellar media method.

such as lower alcohols. Depending on the alcohol concentration the surface tension is varied. ${ }^{16}$ For example, the change of critical micelle concentration $(\mathrm{cmc})$ of SDS in water, depending on the concentration of $\mathrm{EtOH}$ is shown in Figure 1.
The $\mathrm{cmc}$ reaches a minimum at $5 \%$ of EtOH (marked area I), and increases from that point. ${ }^{16}$ The reason for this minimum is association of EtOH with the SDS micelle. But then solubility of SDS increases with an increase in the EtOH concentration. Thus at constant temperature 


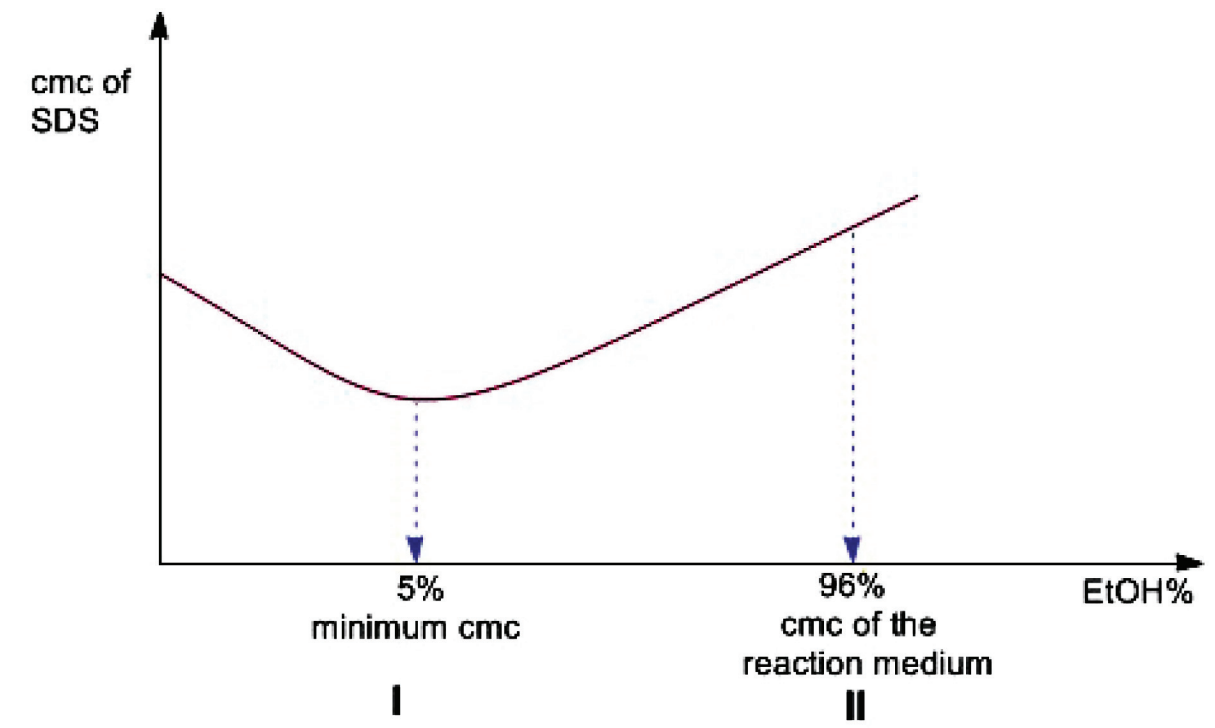

Figure 1. Cmc value of SDS according to EtOH concentration in water.

Table 3. Structures of the synthesized oxadiazoles.

Entry

Ylldırım: Improved Protocol Toward 1,3,4-Oxadiazole-2(3H)-thiones ... 
minor amounts of EtOH lower the cmc of SDS, but when $\mathrm{EtOH}$ is available in large amounts the value rises. ${ }^{17} \mathrm{In} \mathrm{Fi}-$ gure 1 the area marked II shows concentration of EtOH where the reaction takes place.

In comparison with the reported conventional methods for the preparation of oxadiazoles, the present method was found to be advantageous in terms of scale up as well as easy isolation of pure products. On the other hand, this method offers a number of attractive advantages such as short reaction time, non-hazardous solvents, and cost effectiveness. The structures of the oxadiazoles prepared in this study are given in Table 3 . The synthesis of $\mathbf{2} \mathbf{c}^{19-21}$ was performed on a multi-gram scale and high yield of the product was obtained (95\%). ${ }^{1} \mathrm{H}$ NMR and ${ }^{13} \mathrm{C}$ NMR data were in good agreement with the literature. ${ }^{18-27}$

\section{Conclusions}

The present approach furnished mono and bis-1,3,4oxadiazole-2 $(3 H)$-thiones with high yields and is, to the best of my knowledge, the first economically SDS catalyzed route to date to prepare above-mentioned heterocyclic compounds in a convenient manner. The heterocyclic compounds could be obtained from readily available reagents and solvents with simple workup, rendering this improved protocol highly amenable to the large-scale synthesis of 1,3,4-oxadiazole-2(3H)-thiones.

\section{Experimental}

\section{1. General}

All reagents and solvents were purchased from either Merck or Sigma-Aldrich and used without further purification. TLC was performed using silica gel $\left(60 \mathrm{~F}_{254}\right.$, Merck, Darmstadt, Germany) plates. Melting points were recorded by Büchi melting point B-540 apparatus (Büchi Labortechnik AG in Flawil, Switzerland). The NMR spectra were measured using Varian Mercury plus spectrometer $(400 \mathrm{MHz})$ (Varian Inc., California, USA) in $\mathrm{CDCl}_{3}$ using TMS as the internal standard. Chemical shifts (d) are reported in ppm and $J$ values in Hertz.

\section{2. Typical Experimental Procedures for the Synthesis of 5-Substituted-1,3,4 -oxadiazole-2(3H)-thiones}

\section{2. 1. Micellar Media Method (2 $\left.\mathrm{c}^{19-21}\right)$}

Potassium hydroxide $(0.2 \mathrm{~g}, 3.6 \mathrm{mmol})$ was dissolved in $1 \mathrm{~mL}$ of water and absolute ethanol $(25 \mathrm{~mL})$ was added. Hydrazide 1c $(0.6 \mathrm{~g}, 2.2 \mathrm{mmol})$ and SDS (0.06 g, $10 \% \mathrm{mmol} / \mathrm{mmol}$ ) were added to the above basic solution. After the formation of a clear solution, $\mathrm{CS}_{2}(0.3 \mathrm{~g}, 0.24 \mathrm{~m}$ $\mathrm{L}, 3.9 \mathrm{mmol}$ ) was added dropwise and the mixture stirred at reflux for $2 \mathrm{~h}$. The reaction mixture was concentrated under vacuum, and $10 \mathrm{~mL}$ of ice-cooled water was added. Afterwards, the solution was acidified with cooled $1 \mathrm{M}$ $\mathrm{HCl}(\mathrm{aq})$. The obtained solid was filtered under vacuum and dried at room temperature and ambient pressure for $24 \mathrm{~h}$. It was crystallized from $\mathrm{EtOH} / \mathrm{H}_{2} \mathrm{O}$ as a white crystalline solid; yield $0.69 \mathrm{~g}(100 \%)$; mp $83-84^{\circ} \mathrm{C}$; IR (KBr): $3205,1620,1176,1068 \mathrm{~cm}^{-1}$; ${ }^{1} \mathrm{H}$ NMR $(400 \mathrm{MHz}$, $\mathrm{CDCl}_{3}$ ): $\delta 10.93(\mathrm{~s}, 1 \mathrm{H},-\mathrm{NH}), 2.69\left(\mathrm{t}, \mathrm{J} 7.6 \mathrm{~Hz}, 2 \mathrm{H},-\mathrm{CH}_{2}-\right.$ het), 1.74 (quin, J $7.5 \mathrm{~Hz}, 2 \mathrm{H},-\mathrm{CH}_{2} \mathrm{CH}_{2} \mathrm{CH}_{2}$-het), $1.43-1.22\left(\mathrm{~m}, 24 \mathrm{H},-\mathrm{CH}_{2}-\right), 0.87\left(\mathrm{t}, \mathrm{J} 6.4 \mathrm{~Hz}, 3 \mathrm{H},-\mathrm{CH}_{3}\right)$; ${ }^{13} \mathrm{C}$ NMR $\left(100 \mathrm{MHz}, \mathrm{CDCl}_{3}\right): \delta 178.54,164.90,31.87$, $29.54,29.52,29.32,29.29,28.99,28.76,25.67,25.53$, 22.66, 14.10. Anal. Calcd for $\mathrm{C}_{17} \mathrm{H}_{32} \mathrm{~N}_{2} \mathrm{OS}$ : C, 65.34; $\mathrm{H}$, 10.32; N, 8.96; S, 10.26. Found: C, 65.15; H, 10.09; N, $8.49 ; \mathrm{S}, 10.28$.

\section{2. 2. Scale-up of Micellar Media Method $\left(2 c^{19-21}\right)$}

Potassium hydroxide $(6.75 \mathrm{~g}, 120 \mathrm{mmol})$ was dissolved in $25 \mathrm{~mL}$ of water and absolute ethanol $(400 \mathrm{~mL})$ was added. Hydrazide 1c (20 g, $73.9 \mathrm{mmol})$ and SDS $(2.13 \mathrm{~g}, 10 \% \mathrm{mmol} / \mathrm{mmol})$ were added to the above basic solution. After the formation of a clear solution, $\mathrm{CS}_{2}(10$ g, $7.9 \mathrm{~mL}, 131.3 \mathrm{mmol}$ ) was added and the mixture stirred at reflux for $2 \mathrm{~h}$. The reaction mixture was concentrated under vacuum, and $150 \mathrm{~mL}$ of ice-cooled water was added. Afterwards, the solution was acidified with cooled $1 \mathrm{M} \mathrm{HCl}(\mathrm{aq})$. The obtained solid was filtered under vacuum and dried at room temperature and ambient pressure for $24 \mathrm{~h}$. It was crystallized from $\mathrm{EtOH} / \mathrm{H}_{2} \mathrm{O}$ as a white crystalline solid; yield $22 \mathrm{~g}(95 \%)$

\section{3. 3. Conventional Method $\left(2 \mathrm{c}^{19-21}\right)$}

Potassium hydroxide $(0.2 \mathrm{~g}, 3.6 \mathrm{mmol})$ was dissolved in $1 \mathrm{~mL}$ of water and absolute ethanol $(25 \mathrm{~mL})$ was added. Hydrazide 1c $(0.6 \mathrm{~g}, 2.2 \mathrm{mmol})$ was added to the above basic solution. After the formation of a clear solution, $\mathrm{CS}_{2}(0.3 \mathrm{~g}, 0.24 \mathrm{~mL}, 3.9 \mathrm{mmol})$ was added dropwise and the mixture stirred at reflux for $24 \mathrm{~h}$. The reaction mixture was concentrated under vacuum, and $10 \mathrm{~mL}$ of ice-cooled water was added. Afterwards, the solution was

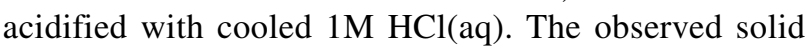
was filtered under vacuum and dried at room temperature and ambient pressure for $24 \mathrm{~h}$. It was crystallized from Et$\mathrm{OH} / \mathrm{H}_{2} \mathrm{O}$ as a white crystalline solid; yield $0.66 \mathrm{~g}(95 \%)$.

\section{References}

1. J. Sun, H. Zhu, Z. M. Yang, H. L. Zhu, Eur. J. Med. Chem. 2013, 60, 23-28.

http://dx.doi.org/10.1016/j.ejmech.2012.11.039

2. A. S. Aboraia, H. M. Abdel-Rahman, N. M. Mahfouz, M. A. El-Gendy, Bioorg. Med. Chem. 2006, 14, 1236-1246. 
http://dx.doi.org/10.1016/j.bmc.2005.09.053

3. V. M. Jakubkienė, M. M. Burbulienè, G. Mekuškiene, E. Udrènaite, P. Gaidelis, P. Vainilavičius, Farmaco 2003, 58, 323-328. http://dx.doi.org/10.1016/S0014-827X(02)00022-8

4. F. Makaev, Z. Ribkovskaia, S. Pogrebnoi, V. Boldescu, G. Rusu, N. Shvets, A. Dimoglo, A. Geronikaki, R. Reynolds, Bioorg. Med. Chem. 2011, 19, 6792-6807. http://dx.doi.org/10.1016/j.bmc.2011.09.038

5. M. A. Quraishi, D. Jamal, Mater. Chem. Phys. 2001, 71, 202-205. http://dx.doi.org/10.1016/S0254-0584(00)00378-3

6. A. Zarghi, Z. Hajimahdi, S. Mohebbi, H. Rashidi, S. Mozaffari, S. Sarraf, M. Faizi, S. A. Tabatabaee, A. Shafiee, Chem. Pharm. Bull. 2008, 56, 509-512. http://dx.doi.org/10.1248/cpb.56.509

7. W. Xianli, Z. Chunfeng, L. Zhidan, W. Chengshi, L. Xincheng, Chin. J. Org. Chem. 2011, 6, 824-831.

8. W. A. El-Sayed, N. M. Fathi, W. A. Gad, El-Sayed H. El-Ashry, J. Carbohydr. Chem. 2008, 27, 357-372.

9. T. E. Nalesnik, Synthesis and use of 5-C1-30-alkyl-2-mercapto-1,3,4-oxadiazoles as ashless lubricating oil extremepressure additives, WO 2002099020 A1, 2002.

10. D. E. Horning, J. M. Muchowski, Can. J. Chem. 1972, 50, 3079-3082. http://dx.doi.org/10.1139/v72-489

11. Y. Zhang, R. Z. Qiao, P. F. Xu, Z. Y. Zhang, Q. Wang, L. M. Mao, K. B. Yu, J. Chin. Chem. Soc. 2002, 49, 369-373.

12. S. A. Shahzad, M. Yar, Z. A. Khan, I. U. Khan, S. A. R. Naqvi, N. Mahmood, K. M. Khan, Eur. J. Chem. 2012, 3, 143- 146. http://dx.doi.org/10.5155/eurjchem.3.2.143-146.551

13. S. Joshi, A. V. Karnik, Synth. Commun. 2002, 32, 111-114. http://dx.doi.org/10.1081/SCC-120001516
14. M. S. Beigi, R. Aryan, M. Yousofizadeh, S. A. Khosravi, Journal of Chemistry 2013, 2013, 6 pp.

15. Z. Liu, J. Zhao, X. Huang, Bioorg. Med. Chem. Lett. 2006, 16, 1828-1830. http://dx.doi.org/10.1016/j.bmcl.2006.01.002

16. D. Myers, Surfactant Science and Technology, $3^{\text {th }}$ Edition, John Wiley \& Sons Inc: Hoboken, New Jersey, 2006, pp. 153-154.

17. B. D. Flockhart, J. Colloid. Sci. 1957, 12, 557-565. http://dx.doi.org/10.1016/0095-8522(57)90061-2

18. K. R. Alagawadi, C. S. Mahajansetti, S. S. Jalalpure, Indian J. Heterocycl. Chem. 2005, 14, 315-318.

19. M. S. Amine, A. M. Feissa,; A. A. El-Sawy, A. F. Shaaban, R. El-Sayed,Olaj, Szappan, Kozmetika 2004, 53, 124-128.

20. H. A. Bhakare, R. R. Khotpal, A. S. Kulkarni, Acta Cienc. Indica Chem. 1997, 23, 101-104.

21. R. C. Badami, S. B. Hendi, K. B. Patil, J. Oil Technologists' Assoc. India 1979, 11, 78-79.

22. K. Futaki, Y. Oyama, T. Iwasaki, Photogr. Sci. Eng. 1960, 4 , 97-100.

23. S. M. Kudari, S. E. Badiger, E. Sangamesh, Asian J. Chem. 1998, 10, 462-466.

24. A. O. Maslat, M. Abussaud, H. Tashtoush, M. Al-Talib, Pol. J. Pharm. 2002, 54, 55-59.

25. S. Toliwal, K. Jadav, K. Patel, Indian J. Pharm. Soc. Sci. 2009, 71, 144-148.

26. M. S. Chande, A. A. Godbole, C. Sajithkumar, Heteroat. Chem. 2003, 14, 273-275. http://dx.doi.org/10.1002/hc.10141

27. C. D. Daulatabad, A. M. Mirajkar, J. Oil Technologists' Assoc. India 1988, 20, 9-11.

\section{Povzetek}

Poročam o priročnem postopku in situ ciklizacije kalijevih hidrazinkarboditioatnih soli v 1,3,4-oksadiazol-2(3H)-tione pod pogoji katalize $\mathrm{v}$ micelnem mediju z normalno fazo ob sodelovanju natrijevega dodecil sulfata (SDS) kot anionskega surfaktanta. Glavna prednost tega postopka je skrajšanje reakcijskih časov, ki so potrebni za popolno ciklizacijo; možno je tudi izvajanje sintez z večjimi količinami; ker je oksadiazole mogoče pripraviti z visokimi do odličnimi izkoristki (87-100\%), to še dodatno poveča zanimivost predstavljenega protokola kot atraktivne alternative obstoječim metodam. 